\title{
Clinical outcomes of medication therapy management services in primary health care
}

\author{
Simone de Araújo Medina Mendonça ${ }^{1}$, Angelita Cristine Melo², Gabriela Cristina Coelho Pereira², \\ Danielle Maria de Souza Serio dos Santos ${ }^{3}$, Elisa Brandão Grossi², Maria do Carmo Vilas Boas \\ Sousa $^{2}$, Djenane Ramalho de Oliveira ${ }^{1}$, Adriana Cristina Soares ${ }^{2 *}$
}

\author{
${ }^{1}$ Federal University of Minas Gerais, UFMG, Belo Horizonte, MG, Brazil, ${ }^{2}$ Federal University São João Del-Rei, UFSJ, \\ Divinópolis, MG, Brazil, ${ }^{3}$ Federal University of Rio de Janeiro, UFRJ, Rio de Janeiro, RJ, Brazil
}

\begin{abstract}
This study evaluates whether the integration of pharmacists into health-care teams through the delivery of pharmaceutical care-based medication therapy management (MTM) services can improve the clinical outcomes of patients with chronic health conditions in the primary health-care setting. A retrospective descriptive study of 92 outpatients assisted by MTM pharmacists in primary health-care units was carried out over 28 months (median follow-up: 05 months). Patients were followed up by MTM pharmacists, with a total of 359 encounters and a ratio of 3.9 encounters per patient. The prevalence of hypertension, diabetes mellitus and dyslipidaemia was $29.5 \%, 22.0 \%$ and $19.4 \%$, respectively. There was a high prevalence of drug-related problems with a ratio of 3.4 per patient. Pharmacists performed a total of 307 interventions to prevent or resolve drug-related problems. With regard to control of the most prevalent chronic medical conditions, a high percentage of patients reached their therapy goals by the last encounter with the pharmacist: $90.0 \%$ for hypertension, $72.3 \%$ for diabetes mellitus and $90.3 \%$ for dyslipidaemia. MTM services provided by pharmacists resolved drug therapy problems and improved patients' clinical outcomes. This study provides evidence for health-care managers of the need to expand the clinical role of pharmacists within the Brazilian public health-care system.
\end{abstract}

Uniterms: Pharmaceutical care/primary care. Medication therapy management. Chronic health/ conditions. Pharmacists/professional practice/Brazil

\section{INTRODUCTION}

In pharmaceutical care practice the pharmacist takes responsibility for meeting patients' drug-related needs by detecting and resolving drug-related problems (DRPs). In this study, this professional practice is materialized into the clinical service known as medication therapy management (MTM). MTM services follow the philosophy and patient care process of pharmaceutical care practice as proposed by Cipolle, Strand and Morley (2012) and, for this reason, they are called "pharmaceutical care-based MTM" (Ramalho de Oliveira, 2009; Obreli Neto et al., 2011; de Souza et al., 2007; Lee, Grace, Taylor, 2006; Cipolle, Strand, Morley, 2012).

Various studies have demonstrated the positive

*Correspondence: A. C. S. Souza. Universidade Federal de São João Del Rei. Av. Sebastião Gonçalves Coelho, 400, Chanadour, 35501-296 - Divinópolis - MG - Brazil. Tel: + 5537 9175-1827. Fax: + 5537 3221-1614. E-mail: adrianasouza@ufsj.edu.br impact of pharmaceutical care practice on patients' health outcomes. A recently published study showed that exposure to face-to-face MTM services resulted in improvement of medication adherence measured by proportion of days covered across multiple chronic disease medication classes (Brummel, Carlson, 2016). Fikri-Benbrahim et al. (2013) showed that adherence to antihypertensive therapy in a pharmacist intervention group was 4.07 times higher than in a control group. Tan et al. (2014) demonstrated that the integration of pharmacists into primary care clinics had positive effects on primary outcomes related to medication use or clinical outcomes. Strand et al. (2004) showed that $88.0 \%$ of patients' DRPs were resolved by pharmacists, while Borges et al. (2010) successfully resolved $62.7 \%$ of the identified DRPs.

Despite the potential impact of pharmaceutical care on medication use, and while professionals and researchers in developed countries are involved in understanding and improving the sustainability of MTM 
services (Sorensen et al., 2016), these are still limited in developing countries such as Brazil. Pharmacists in developing countries work mainly in activities related to acquisition and inventory control of drugs, with little involvement in direct patient care (Obreli Neto et al., 2011). There are a few published studies on the clinical outcomes of this practice in Brazil, mainly in the primary care setting (Mourão et al., 2013; Obreli Neto et al., 2011; Obreli Neto, Cuman, 2010; Lyra Júnior, Marcellini, Pelá, 2008; de Souza et al., 2007; Lyra Júnior et al., 2007).

Primary care is the main option for access to health care for approximately $70 \%$ of the Brazilian population (Obreli Neto et al., 2011). In primary care, the high prevalence of chronic conditions is associated with an increase in the use of medications Obreli Neto et al., 2011; Lee, Grace, Taylor, 2006). Also, the high use of medications is associated with the development of DRPs, which can negatively impact on patients' health and increase the total health-care costs (Obreli Neto et al., 2011; Lee, Grace, Taylor, 2006; Cipolle, Strand, Morley, 2012).

The aim of this study was to evaluate whether the integration of pharmacists into health-care teams through the delivery of pharmaceutical care-based medication therapy management services can improve the clinical outcomes of patients with chronic health conditions in the primary care setting.

\section{PATIENTS AND METHODS}

A retrospective descriptive study was conducted including all patients $(\mathrm{n}=92)$ assisted by MTM pharmacists in primary health-care units in Divinópolis (MG, Brazil) between October 2010 and February 2013.

\section{Ethical approval}

The study was conducted following the Declaration of Helsinki guidelines (WMO, 1996) and the provisions of the Brazilian National Health Committee. The Institutional Human Experimentation Committee of UFSJ (No. 007/2011) approved it.

\section{Setting}

MTM services were provided in three units of the Family Health Strategy (FHS) in the city of Divinópolis, Minas Gerais, Brazil. Two clinical faculties, three pharmacy students and one pharmacist from the local health system composed the team. The criteria for patient referral to the MTM service were: multiple medication use (two or more medications), old age ( $\geq 60$ years), lack of response to treatment, presence of adverse drug reactions and non-adherence to the prescribed treatment. Patients were eligible if they met at least one criterion. The number and frequency of appointments were individualized according to the patient's needs (weekly, fortnightly or monthly) and the interventions were implemented either directly with the patient or with the physician.

\section{Data collection and analysis}

Data were collected from the patient's medical record. The first consultation was called "before initiating delivery of MTM services" and "abandonment of service" or "final data collection (February of 2013)" was identified as "after delivery of MTM services". A coded structured instrument was constructed, which included: clinical conditions according to the International Classification of Diseases-10 (WHO, 1992), pharmacotherapy utilized [according to the Anatomical Therapeutic Chemical Code (WHO, 2012), medicine dosage forms and duration of treatment], clinical status of the patient according to the established goals of therapy, DRPs, interventions implemented by the pharmacist and the therapy goals achieved. The data were stratified by polypharmacy (use of five or more medications) according to Flores and Mengue (2005).

To analyze the results, we used the theoretical framework proposed by Cipolle, Strand and Morley (2012) for the description of the pharmacotherapeutic needs, types of DRPs and the categorization of pharmacist interventions. The following parameters were utilized in assessing whether or not the therapy goals were met: hypertension, blood pressure $\leq 139 / 89$ mmHg (Dipiro et al., 2011); type 2 diabetes mellitus, pre- and postprandial glucose levels of $<130 \mathrm{mg} / \mathrm{dL}$ and $<180 \mathrm{mg} / \mathrm{dL}$, respectively (Dipiro et al., 2011); hyperlipidaemia, LDL $<130 \mathrm{mg} / \mathrm{dL}$ (Semla, Beizer, Higbee, 2012); anxiety disorder, absence of insomnia, muscle tension, irritability or restlessness (Young et al., 2005); major depression, absence of changes in sleep, appetite, daily accomplishment of tasks, absence of distress and suicide ideation (Young et al., 2005); osteoporosis, the absence of fractures, reduction of pain, increase in functional capacity and maintenance of bone mass (Dipiro et al., 2011); pain, absence of pain (Dipiro et al., 2011); hypothyroidism, free $\mathrm{T} 4$ in the range of $5.0-12.0 \mathrm{mcg} / \mathrm{dL}$ and TSH in the range of $0.4-4.5 \mathrm{mU} / \mathrm{L}$ (Young et al., 2005); dyspepsia, lack of heartburn and stomach discomfort (Dipiro et al., 2011); and epilepsy and absence of seizure (Dipiro et al., 2011). 
As proposed by Cipolle, Strand and Morley (2012), in this study the health status was used to measure patients' clinical outcomes. The clinical outcome status of each of the patients' medical conditions was assessed by the research team at the last MTM visit and compared with the baseline health status using data from the patient's medical record. The baseline health status was classified as positive when the health condition was controlled and negative when it was not controlled. According to Cipolle, Strand and Morley (2012), the clinical outcome status at the last MTM visit was considered positive when it was classified as "resolved", "stable", "improved" or "partially improved". The following categories were used when the clinical status was considered negative: "no improvement", "worsened", "therapeutic failure" and "death".

For data analysis, the database was set up using the technique of double entry and processed using the Statistical Package for the Social Sciences (SPSS - version 22). Statistics consisted of measures of central tendency, variability and proportions. McNemar's test was used to verify the effect of pharmacist intervention. This test examines treatment effect and tests the hypothesis that the change in proportions between the different time points is due to chance. Thus, when we reject this hypothesis, we can say that there is evidence of a treatment effect (Pagano, Gauvreau, 2004).

\section{RESULTS}

The median age of patients was 63.0 years and $67.4 \%(n=62)$ were females. With regard to the follow-up of patients, there were 359 consultations with a median of 3.9 per patient. Three hundred and twenty health problems were found, with a median of 3.5 per patient.

Ten medical conditions represented $83.8 \%(n=268)$ of the total reported. The most prevalent medical conditions were: hypertension (29.5\%), type 2 diabetes mellitus (22.0\%) and dyslipidemia (19.4\%). Dyspepsia, type 2 diabetes mellitus and dyslipidemia had the greatest proportion of patients who had uncontrolled disease: $80.0 \%, 66.0 \%$ and $54.1 \%$, respectively (Table I).

Most medications were prescribed for the treatment and control of non-communicable diseases (NCDs) such as hypertension, diabetes and dyslipidemia. The 15 most commonly used drugs accounted for $65.3 \%$ of the total number of drugs (Table II). On average, each patient used 6.0 different medications.

During MTM visits, 316 DRPs were detected with an average of 3.4 DRPs per patient and $88.6 \%$ of DRPs were related to polypharmacy. The most prevalent DRP was adverse reaction $(31.0 \%)$ (Table III).
The causes of DRPs were the following: $24.1 \%$ $(\mathrm{n}=71)$ undesirable effect, unsafe medication, presence of a contraindication and treatment of preventable adverse reactions; $22.4 \%(\mathrm{n}=66)$ drug interactions; $7.8 \%(\mathrm{n}=23)$ frequency, dosage and/or incorrect administration; $7.5 \%$ $(\mathrm{n}=22)$ lack of clinical indication; 6.1\% $(\mathrm{n}=18)$ patient preference for drug cessation; $5.8 \%(\mathrm{n}=17)$ patient failure to understand instructions; $4.8 \%(\mathrm{n}=14)$ high dose; $4.4 \%$ $(\mathrm{n}=13)$ duplicate therapy; $4.1 \%(\mathrm{n}=12)$ ineffective dose (low dose); $3.7 \%(\mathrm{n}=11)$ more effective drug available or the drug is not indicated for the condition; and $9.5 \%(n=28)$ were related to other problems.

A total of 307 interventions were performed, and most of them contributed to the achievement of the patient's therapeutic goal. The most common intervention was medication change (Table IV).

At the beginning of the MTM service (at baseline), the clinical status of the patients' medical conditions was considered negative in almost half of the times, $47.5 \%$. After the service was delivered, the final evaluation showed that $83.9 \%(\mathrm{n}=156)$ of the clinical status was positive (Table I). In $21.2 \%(n=65)$ of interventions there was no record about its impact on the goal of therapy.

\section{DISCUSSION}

The high prevalence of polypharmacy in this study can be explained by the fact that it was one of the criteria for referral to MTM services. However, the high prevalence of chronic diseases also contributed to polypharmacy (Sousa et al., 2012; Flores, Mengue, 2005). The high incidence of DRPs in patients with polypharmacy has also been shown in other studies (Correr et al., 2007; Koh et al., 2005).

The therapeutic goal at the first MTM visit of most of the health conditions associated with polypharmacy, especially hypertension, diabetes and dyslipidaemia, was not being achieved. As shown in the present study and in previously published research, MTM services represent an effective strategy for the resolution of DRPs, which can significantly improve patients' clinical outcomes (Tan et al., 2014; Fikri-Benbrahim et al., 2013; Zaman Huri, Chai Ling, 2013; Mourão et al., 2013; Obreli Neto et al., 2011; Alencar et al., 2011; Correr et al., 2011; Borges et al., 2010; Obreli Neto, Cuman, 2010). In a study examining 10 years of pharmaceutical care services in Minnesota, Ramalho de Oliveira et al. (2010) also pointed out the importance of pharmacist-delivered medication management services for the control of hypertension, diabetes and dyslipidemia.

Interestingly, in the case of psychiatric disorders, 
TABLE I - Analysis of patients regarding the clinical outcome status of their medical conditions before and after initiating the delivery of MTM services, stratified by polypharmacy

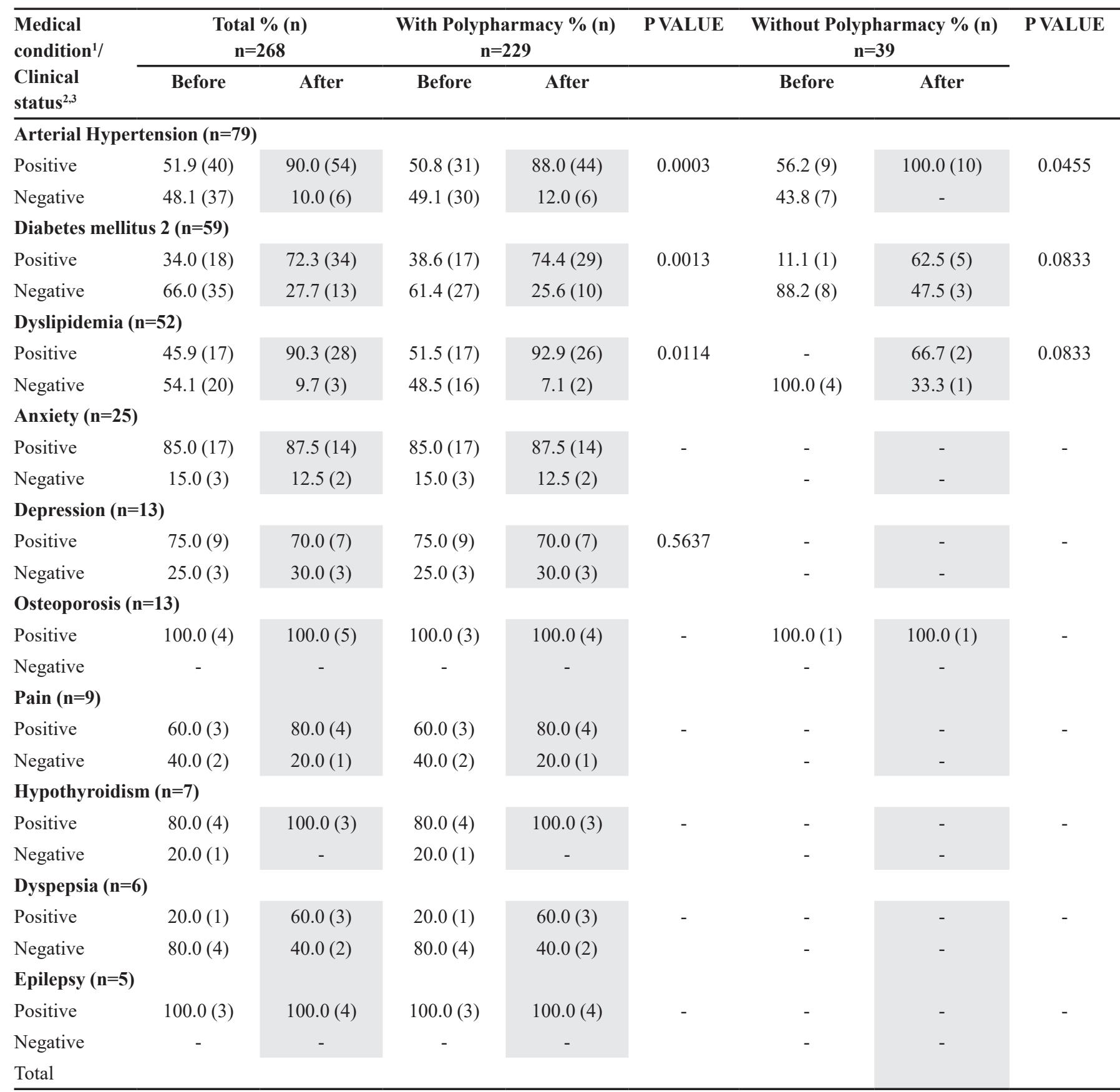

\footnotetext{
${ }^{1}$ Number of patients with medical conditions stratified by clinical status and polypharmacy (in the column). ${ }^{2}$ The classifications of clinical status named controlled (first appointment) or resolved, stable, improvement and partial improvement (last appointment) were aggregated as POSITIVE, and the classifications not controlled (first appointment) or no improvement, worsening, therapeutic failure and death (last appointment) were aggregated as NEGATIVE. ${ }^{3}$ There are patients whose therapeutic goal records, or clinical status, in the first and last MTM visit were not described.
}

there was not much difference in the attainment of therapeutic goals before and after service delivery. This may reflect the difficulty in objectively measuring clinical results or a deficiency in the skills of pharmacists in evaluating the subjective parameters utilized in mental health. In the case of osteoporosis, all patients were taking alendronate sodium and were achieving their therapeutic goals at the beginning of the study. The 
TABLE II - Most used medications by patients referred to medication therapy management services, stratified by polypharmacy

\begin{tabular}{lccc}
\hline Medication & $\begin{array}{c}\text { Total } \mathbf{\%}^{\mathbf{1}} \mathbf{( n )} \\
\mathbf{n = 4 0 2}\end{array}$ & $\begin{array}{c}\text { With Polypharmacy } \mathbf{\%}^{\mathbf{2}} \text { (n) } \\
\mathbf{n}=\mathbf{3 4 4}\end{array}$ & $\begin{array}{c}\text { Without Polypharmacy } \mathbf{\%}^{\mathbf{2}} \text { (n) } \\
\mathbf{n}=\mathbf{5 8}\end{array}$ \\
\hline Simvastatin & $12.7(51)$ & $86.3(44)$ & $13.7(7)$ \\
Metformin & $11.9(48)$ & $79.2(38)$ & $20.8(10)$ \\
Hydrochlorothiazide & $11.4(46)$ & $73.9(34)$ & $26.1(12)$ \\
Captopril & $10.0(40)$ & $80.0(32)$ & $20.0(8)$ \\
AAS & $8.0(32)$ & $87.5(28)$ & $12.5(4)$ \\
Insulin NPH & $7.0(28)$ & $96.4(27)$ & $3.6(1)$ \\
Losartan & $8.0(27)$ & $88.9(24)$ & $11.1(3)$ \\
Glyburide & $6.5(26)$ & $73.1(19)$ & $26.9(7)$ \\
Nifedipine extended-release & $5.0(21)$ & $85.7(18)$ & $14.3(3)$ \\
Furosemide & $4.2(17)$ & $100.0(17)$ & - \\
Propranolol & $3.7(15)$ & $93.3(14)$ & $6.7(1)$ \\
Omeprazole & $3.7(15)$ & $86.7(13)$ & $13.3(2)$ \\
Clonidine & $3.0(12)$ & $100.0(12)$ & - \\
Alendronate Sodium & $3.0(12)$ & $100.0(12)$ & - \\
Spironolactone & $3.0(12)$ & $100.0(12)$ & - \\
\hline
\end{tabular}

${ }^{1}$ Calculated estimates considering the column totals. ${ }^{2}$ Calculated estimates considering the row totals in order to compare "with" and "without" polypharmacy.

TABLE III - Profile of DRPs stratified by polypharmacy

\begin{tabular}{|c|c|c|c|c|}
\hline Pharmaceutical needs ${ }^{1}$ & Types of DRP & $\begin{array}{c}\text { Total \% (n) } \\
\quad n=316\end{array}$ & $\begin{array}{c}\text { With Polypharmacy } \\
\% \text { (n) } \\
\mathbf{n}=\mathbf{2 8 0}\end{array}$ & $\begin{array}{c}\text { Without Polypharmacy } \\
\text { \% (n) } \\
\mathbf{n}=36\end{array}$ \\
\hline \multirow[t]{2}{*}{ Indication } & Unnecessary medication & $15.5(49)$ & $91.8(45)$ & $8.2(4)$ \\
\hline & $\begin{array}{l}\text { Need for additional } \\
\text { medication }\end{array}$ & $5.1(16)$ & $81.3(13)$ & $18.7(3)$ \\
\hline \multirow[t]{2}{*}{ Effectiveness } & Medicine ineffective & $5.1(16)$ & $87.5(14)$ & $12.5(2)$ \\
\hline & Low Dose & $18.0(57)$ & $86.0(49)$ & $14.0(8)$ \\
\hline \multirow[t]{2}{*}{ Safety } & Adverse reaction & $31.0(98)$ & $89.9(88)$ & $10.1(10)$ \\
\hline & High Dose & $12.0(38)$ & $97.4(37)$ & $2.6(1)$ \\
\hline Adherence & Non-adherence & $13.3(42)$ & $81.0(34)$ & $19.0(8)$ \\
\hline
\end{tabular}

'Pharmacotherapies

parameters used to assess the effectiveness of treatment were the absence of pain, fractures and an increase in functional capacity. One limitation of the study was that bone densitometry was not performed at the beginning or at the end of the service. However, patients receiving MTM did not have access to this examination, and the goal of this study was to evaluate the impact of MTM services in real life. This limitation is conservative for the purposes of the study, since it points to an underestimate of the effectiveness of MTM services.
Adverse drug reactions were the most prevalent DRP in the present study. The patient's attitudes toward medications, which reflect a personal evaluation of the drug as good or bad and harmful or beneficial, are thought to influence behaviour and adherence (Lyra Júnior et al., 2007; Mardby, Akerlind, Jorgensen, 2007; Phatak, Thomas, 2006; Osterberg, Blaschke, 2005; WHO, 2003; Ajzen, 2001; Petty, Wegener, Fabrigar, 1997). A study by Correr et al. (2007) found that the safety of the treatment was the most significant risk factor for DRPs. 
TABLE IV - Interventions carried out during delivery of medication therapy management services and therapeutic goals achieved

\begin{tabular}{lccc}
\hline Intervention performed & $\begin{array}{c}\text { Total } \\
\mathbf{\%}(\mathbf{n}) \\
\mathbf{n = 3 0 7}\end{array}$ & $\begin{array}{c}\text { Therapeutic goal } \\
\text { achieved \%(n) } \\
\mathbf{n = 2 0 2}\end{array}$ & $\begin{array}{c}\text { Therapeutic goal not achieved } \\
\mathbf{\%}(\mathbf{n}) \\
\mathbf{n = 4 0}\end{array}$ \\
\hline Change medicine & $22.1(68)$ & $84.2(48)$ & $15.8(9)$ \\
Interrupt pharmacotherapy & $16.3(50)$ & $75.0(27)$ & $25.0(9)$ \\
Patient instructions * & $16.0(49)$ & $79.4(27)$ & $20.6(7)$ \\
Change dose & $11.1(34)$ & $75.0(18)$ & $25.0(6)$ \\
Remove barriers to treatment & $9.8(30)$ & $96.2(26)$ & $3.7(1)$ \\
adherence & & & $24.0(6)$ \\
Start monitoring of adverse & $8.1(25)$ & $76.0(19)$ & $5.9(1)$ \\
reaction & & $94.1(16)$ & $9.1(1)$ \\
Start laboratory monitoring & $6.8(21)$ & $90.9(10)$ & $0.0(0)$ \\
Start new pharmacotherapy & $4.9(15)$ & $100.0(11)$ & \\
Provide reminders with & $4.9(15)$ & & \\
timetables for medicines & & & \\
\hline
\end{tabular}

* Appropriate medication use, nutrition education and information about physical activity.

Adverse drug reactions can be associated with negative clinical outcomes in patients with chronic diseases, so interventions to solve this problem are very important (Gastelurrutia et al., 2011). A high occurrence of adverse drug reactions can lead to higher rates of treatment interruption (Vasconcelos et al., 2005; Firmo, Lima-Costa, Uchôa, 2004). Other authors pointed out the relationship between polypharmacy, adverse drug reactions and nonadherence (Secoli, 2010; Rocha et al., 2008; Rozenfeld, 2003).

Changes or recommendations for a change of a patient's medication were the most common intervention to resolve the DRPs of adverse drug reactions. For instance, many patients were on captopril $(n=40)$ and had presented with a dry cough. Also, a significant number of patients were using clonidine ( $\mathrm{n}=12)$ - mainly men, who complained about adverse reactions such as dry mouth, bradycardia and impotence, and abandoned the treatment due to these effects. Clonidine is mentioned in the Beers criteria as a drug that has a high risk of adverse effects, including those that affect the central nervous system, orthostatic hypotension and bradycardia. It is interesting to note that the mean age of our patients was 63 years, which is considered elderly in Brazil, and clonidine should not be routinely used for the treatment of hypertension in this population (Gastelurrutia et al., 2011). Therefore, the pharmacist recommended that the physician change the antihypertensive drug to a safer medication.

It was found that many diabetic patients were using non-selective beta blockers such as propranolol $(n=10)$, which is contraindicated in these patients because of the difficulty in identifying symptoms of, and recovering from, hypoglycemia (Dipiro et al., 2011). In this case, a change to a selective beta blocker such as atenolol was recommended. Also, in some cases, a switch from metformin $850 \mathrm{mg}$ once daily to metformin $500 \mathrm{mg}$ slow release twice daily was suggested, depending on the occurrence of gastrointestinal intolerance (Dipiro et al., 2011; Young et al., 2005).

The DRP of low dose was also common, with the most frequent cause being an interaction between captopril and food. This result is in agreement with other studies, which also found that a low dose was the most prevalent DRP in clinical pharmacy services (Correr et al., 2007; Strand et al., 2004). The collaboration between pharmacists and physicians was essential in resolving and/or preventing DRPs in this study. The physicians were receptive to MTM pharmacists' interventions. Collaborative working relationships were developed over time as MTM pharmacists started taking more responsibility for patient care and demonstrated competency.

The significant clinical impact of pharmaceutical care-based MTM, as shown by the improvement in the clinical status of the most prevalent health conditions from the first to the last MTM visit, should be highlighted. As previously underscored (Strand et al., 2004; Ramalho de Oliveira, Brummel, Miller, 2010), these positive results can be partly explained by the inclusion of a professional, an MTM pharmacist, whose main responsibility is to 
improve drug therapy outcomes through collaboration with the patient and the health-care team. Moreover, this professional follows a standardized practice and a logical decision-making process that is based on science and reproducible in the real world.

The use of patient records as a source of information is another limitation of this study, as reported by other authors (Kahn, Ranade, 2010). This emphasizes the need for an improvement in the documentation process, as demonstrated by other authors (Sousa et al., 2012; Kahn, Ranade, 2010; Becker, Bjornson, Kuhle, 2004).

\section{CONCLUSIONS}

The study showed that a large proportion of patients using medications in the primary care setting were not reaching their therapy goals when cared for by the traditional health-care team. The management of patients' drug therapy by MTM pharmacists improves the control of medical conditions, particularly chronic conditions. There was a positive association between polypharmacy and occurrence of DRPs, demonstrating that polypharmacy should be a criterion for the referral of patients to MTM services. Considering that in this study most drugs were used to treat chronic conditions such as hypertension, diabetes and hyperlipidemia, the effective training of pharmacists in these conditions and their treatments might positively affect the health outcomes in primary care. The Brazilian public health system needs to adopt measures to improve control and prevent aggravation of chronic health conditions, and the provision of MTM services might be one of these measures.

\section{ACKNOWLEDGEMENTS}

The authors would like to thank the government of the municipality of Divinópolis for its support for the development of medication therapy management services in the city's primary health-care units. One pharmacist was made available for the project, which enabled the integration of faculties, students and the unit's health-care providers.

Funding: The entire study was financially supported by FAPEMIG (APQ-02867-11).

\section{REFERENCES}

AJZEN, I. Nature and operation of attitudes. Annu. Rev. Psychol., v.52, p.27-58, 2001.
ALENCAR, T.O.S.; BASTOS, V.P.; ALENCAR, B.R.; FREITAS, I.V. Pharmaceutical dispensing: an analysis of legal concepts in relation to professional practice. Rev. Ciênc. Farm. Básica Apl., v.32, p.89-94, 2011.

BECKER, C.L.; BJORNSON, D.C.; KUHLE, J.W. Pharmacist care plans and documentation of follow-up before the Iowa pharmaceutical case management program. J. Am. Pharm. Assoc., v.44, n.3, p.350-357, 2004.

BORGES, A.P.; GUIDONI, C.M.; FERREIRA, L.D.; DE FREITAS, O.; PEREIRA, L.R. The pharmaceutical care of patients with type 2 diabetes. Pharm. W. Sci., v.32, n.6, p.730-736, 2010.

BRUMMEL, A.; CARLSON, A.M. Comprehensive Medication Management and Medication Adherence for Chronic Conditions. J. Manag. Care Spec. Pharm., v.22, n.1, p.56$62,2016$.

CIPOLLE, R.J.; STRAND, L.M.; MORLEY, P.C. Pharmaceutical Care Practice: The Patient-Centered Approach to Medication Management. 3. ed. New York, NY: McGraw Hill Professional, 2012. 697p.

CORRER, C.J.; PONTAROLO, R.; FERREIRA, L.C.; BAPTISTÃO, S.A.M. Drug-related problems risks in patients of a geriatric institution. Braz. J. Pharm. Sci., v.43, n.1, p.55-62, 2007.

CORRER, C.J.; MELCHIORS, A.C.; FERNANDEZ-LLIMOS, F.; PONTAROLO, R. Effects of pharmacotherapy follow-up in community pharmacies on type 2 diabetes in Brazil. Int. J. Clin. Pharm., v.33, n.2, p.273-280, 2011.

DE SOUZA, W.A.; YUGAR-TOLEDO, J.C.; BERGSTENMENDES, G.; SABHA, M.; MORENO, H.JR. Effect of pharmaceutical care on blood pressure control and healthrelated quality of life in patients with resistant hypertension. Am. J. Health-Syst. Pharm., v.64, n.18, p.1955-1961, 2007.

DIPIRO, J.; TALBERT, R.L.; YEE, G.; MATZKE, G.; WELLS, B.; POSEY, L.M. Pharmacotherapy: a pathophysiologic approach. 8. ed. New York, NY: McGraw-Hill, 2011. 2668p.

FIRMO, J.A.O.; LIMA-COSTA, M.F.; UCHÔA, E. Projeto Bambuí: maneiras de pensar e agir de idosos hipertensos. Cad. Saúde Públ., v.20, n.4, p.1029-1040, 2004. 
FIKRI-BENBRAHIM, N.; FAUS, M.J.; MARTÍNEZMARTÍNEZ, F.; SABATER-HERNÁNDEZ, D. Impact of a community pharmacists' hypertension-care service on medication adherence. The AFenPA study. Res. Soc. Adm. Pharm., v.9, n.6, p.797-805, 2013.

FLORES, L.M.; MENGUE, S.S. Drug use by the elderly in Southern Brazil. Rev. Saúde Públ. Brasil., v.39, n.6, p.924929, 2005.

GASTELURRUTIA, P.; BENRIMOJ, S.I.; ESPEJO, J.; TUNEU, L.; MANGUES, M.A.; BAYES-GENIS, A. Negative clinical outcomes associated with drug-related problems in heart failure (HF) outpatients: impact of a pharmacist in a multidisciplinary HF clinic. J. Card. Fail., v.17, n.3, p.217-223, 2011.

KAHN, M.G.; RANADE, D. The impact of electronic medical records data sources on an adverse drug event quality measure. J. Am. Med. Inform. Assoc., v.17, n.2, p.185-191, 2010.

KOH, Y.; MOIDEEN, F.B.; KUTTY; LI,S.C. Drug-related problems in hospitalized patients on polypharmacy: the influence of age and gender. Ther. Clin. Risk Manag., v.1, n.1, p.39-48, 2005.

LEE, J.K.; GRACE, K.A.; TAYLOR, A.J. Effect of a pharmacy care program on medication adherence and persistence, blood pressure, and low-density lipoprotein cholesterol. JAMA, v.296, n.21, p.2563-2571, 2006.

LYRA JÚNIOR, D.P.; ROCHA, C.E.; ABRIATAm J.P.; GIMENES, F.R.; GONZALEZ, M.M.; PELÁ, I.R. Influence of Pharmaceutical Care intervention and communication skills on the improvement of pharmacotherapeutic outcomes with elderly Brazilian outpatients. Patient Educ .Couns., v.68, n.2, p.186-192, 2007.

LYRA JÚNIOR, D.P.; KHEIR, N.; ABRIATA, J.P.; DA ROCHA, C.E.; DOS SANTOS, C.B.; PELÁ, I.R. Impact of Pharmaceutical Care interventions in the identification and resolution of drug-related problems and on quality of life in a group of elderly outpatients in Ribeirão Preto (SP), Brazil. Ther. Clin. Risk Manag., v.3, n.6, p.989-998, 2007.

LYRA JÚNIOR, D.P.; MARCELLINI, P.S.; PELÁ, I.R. Effect of pharmaceutical care intervention on blood pressure of elderly outpatients with hypertension. Rev. Bras. Ciênc. Farm., v.44, n.3, p.451-457, 2008.
MARDBY, A.C.; AKERLIND, I.; JORGENSEN, T. Beliefs about medicines and self-reported adherence among pharmacy clients. Patient Educ. Couns., v.69, n.1-3, p.158164, 2007.

MOURÃO, A.O.; FERREIRA, W.R.; MARTINS, M.A.; REIS, A.M.; CARRILLO, M.R.; GUIMARÃES, A.G.; EV, L.S. Pharmaceutical care program for type 2 diabetes patients in Brazil: a randomised controlled trial. Int. J. Clin. Pharm., v.35, n.1, p.79-86, 2013.

OBRELI NETO, P.R.; CUMAN, R.K. Pharmaceutical care program for the rational use of drugs in the elderly users of a Basic Health Unit in the Sao Paulo State, Brazil. Lat. Am. J. Pharm., v.29, n.3, p.333-339, 2010.

OBRELI NETO, P.R.; MARUSIC, S.; DE LYRA JÚNIOR, D.P.; PILGER, D.; CRUCIOL-SOUZA, J.M.; GAETI, W.P.; CUMAN, R.K. Effect of a 36-month Pharmaceutical Care program on coronary heart disease risk in elderly diabetic and hypertensive patients. J. Pharm. Pharm. Sci., v.14, n.2, p.249-263, 2011.

OSTERBERG, L.; BLASCHKE, T. Adherence to medication. N. Engl. J. Med., v.353, p. 487-497, 2005.

PAGANO, M.; GAUVREAU, K. Principles of biostatistics. São Paulo, SP: Thomson Pioneira, 2004.

PETTY, R.E.; WEGENER, D.T.; FABRIGAR, L.R. Attitudes and attitude change. Ann. Rev. Psychol., v.48, p.609-647, 1997.

PHATAK, H.M.; THOMAS, J. Relationship between beliefs about medications and nonadherence to prescribed chronic medication. Ann. Pharmacother. v.40, n.10, p.1737-1742, 2006.

RAMALHO DE OLIVEIRA, D. The reality of pharmaceutical care-based medication therapy management: patients', pharmacists'and students'perspectives. Saarbrucken: Lambert Academic Publishing. 2009. 384p.

RAMALHO DE OLIVEIRA, D.; BRUMMEL, A.R.; MILLER, D.B. Medication therapy management: 10 years of experience in a large integrated health care system. $J$. Manag. Care Pharm., v.16, n.3, p.185-195, 2010. 
ROCHA, C.H.; DE OLIVEIRA, A.P.S.; FERREIRA, C.; FAGGIANI, F.T.; SCHROETER, G.; DE SOUZA, A.C.A.; DECARLI, G.A; MORRONE, F.B.; WERLANG, M.C. Medication adherence of elderly in Porto Alegre, RS. Ciênc Saúde Colet., v.13, p.703-710, 2008.

ROZENFELD, S. Prevalência, fatores associados e mau uso de medicamentos entre os idosos: uma revisão. Cad. Saúde Públ., v.19, n.3, p.717-724, 2003.

SECOLI, R.S. Polifarmácia: interações e reações adversas no uso de medicamentos por idosos. Rev. Bras. Enferm., v.63, n.1, p.136-140, 2010.

SEMLA, T.P.; BEIZER, J.L.; HIGBEE, M.D. Geriatric dosage handbook. 18. ed. Hudson, Ohio: Lexi Comp, 2012.

SOUSA, M.C.V.B.; MELO, A.C.; SANTOS, D.M.S.S.; PEREIRA, M.L.; SOARES, A.C. Analysis of elderly individuals' access to and utilization of health services and prescription drugs and their patterns of use. Lat. Am. J. Pharm., v.31, n.10, p.1379-1386, 2012.

SORENSEN, T.D.; PESTKA, D.; SORGE, L.A.; WALLACE, M.L.; SCHOMMER, J. The qualitative assessment of medication management services in six health systems Minnesota. Am. J. Health Syst. Pharm., v.73, n.5, p.307314, 2016.

STRAND, L.M.; CIPOLLE, R.J.; MORLEY, P.C.; FRAKES, M.J. The impact of pharmaceutical care practice on the practitioner and the patient in the ambulatory practice setting: twenty-five years of experience. Curr. Pharm. Des., v.10, n.31, p.3987-4001, 2004.

TAN, E.C.K.; STEWART, K.; ELLIOTT, R.A.; GEORGE, J. Pharmacist services provided in general practice clinics: a systematic review and meta-analysis. Res. Soc. Adm. Pharm., v.10, n.4, p.608-622, 2014.
VASCONCELOS, F.F.; VICTOR, J.F.; MOREIRA, T.M.M.; ARAÚJO, T.L. Use of medication for seniors of a basic unit of health of the family of Fortaleza - CE. Acta Paul. Enferm., v.18, n.2, p.78-83, 2005.

WORLD HEALTH ORGANIZATION. WHO. International statistical classification of diseases and related health problems (ICD-10). 10. rev. Geneva, Switzerland, 1992. Available at: < http://apps.who.int/classifications/icd10/ browse/2010/en>. Accessed on: March 2014.

WORLD HEALTH ORGANIZATION. WHO. Collaborating centre for drug statistics methodology. Norwegian Institute of Public Health. Guidelines for ATC classification and DDD assignment 2013. Olso, 2012. Availble at: <http:// www.whocc.no/atc_ddd_index/>. Accessed on: March 2014.

WORLD HEALTH ORGANIZATION. WHO. Adherence to long-term therapies: evidence for action. Geneva, Switzerland, 2003. Available at: <http://whqlibdoc.who. int/publications/2003/9241545992.pdf>. Accessed on: March 2014.

WORLD MEDICAL ORGANIZATION. WMO. Declaration of Helsinki. BMJ, v.313, p.1448-1449, 1996.

YOUNG, L.Y.; KODA-KIMBLE, M.A.; KRADJAN, W.A.; GUGLIELMO, B.J. Manual de terapêutica aplicada [Guide of applied therapeutics]. 7 ed. Rio de Janeiro, RJ: Guanabara Koogan, 2005.

ZAMAN HURI, H.; CHAI LING, L. Drug-related problems in type 2 diabetes mellitus patients with dyslipidemia. $B M C$ Pub. Health, v.13, p.1192-1204, 2013.

Received for publication on $02^{\text {nd }}$ February 2015 Accepted for publication on $15^{\text {th }}$ August 2016 
